\title{
Conservation process of archaeological waterlogged wood studied by spectroscopy and gradient NMR methods
}

\author{
Joanna Kowalczuk ${ }^{1}$. Adam Rachocki ${ }^{1} \cdot$ Magdalena Broda $^{2}$. \\ Bartłomiej Mazela ${ }^{2}$. Graham A. Ormondroyd ${ }^{3}$. Jadwiga Tritt-Goc ${ }^{1}[$
}

Received: 10 June 2019 / Published online: 19 October 2019

(c) The Author(s) 2019

\begin{abstract}
The properties of methyltrimethoxysilane-treated, waterlogged archeological elm wood were studied by magnetic resonance imaging and nuclear magnetic resonance (NMR) methods. The spatially resolved proton density images, spin-spin relaxation profiles, proton NMR spectra, and self-diffusion coefficients of the preservative agents were measured during drying. The resolution of the data allowed for the differentiation between the early and late wood areas of the elm wood and determination of the shrinkage of the sample in the tangential and radial directions, and it showed the different dynamics of methyltrimethoxysilane (MTMS) in the lumen cells of both early and late woods. The NMR spectra indicated that the MTMS, after rapid evaporation of ethanol, is bound to the wood. Identical measurements were also taken for the archeological elm wood treated with polyethylene glycol (PEG) and for an untreated wood sample. From the results, it can be concluded that MTMS showed significantly higher stability against shrinkage when compared to PEG. Therefore, it may be considered as an alternative preservative for archeological wood.
\end{abstract}

\section{Introduction}

Waterlogged archaeological wood is most often characterized by a high degree of degradation, but it retains its shape and dimensions due to the presence of water that fills cell lumen and voids within the wood tissue. However, when wood is removed from water and placed in a dry atmosphere, the rapid evaporation of water leads

Jadwiga Tritt-Goc

jtg@ifmpan.poznan.pl

1 Institute of Molecular Physics Polish Academy of Sciences, M. Smoluchowskiego 17, 60-179 Poznan, Poland

2 Faculty of Wood Technology, Poznań University of Life Sciences, Wojska Polskiego 38/42, 60-627 Poznan, Poland

3 BioComposites Centre, Bangor University, Bangor, UK 
to its further destruction resulting in shrinkage, cracking, and deformation (Siau 1984; Bugani et al. 2009). The only way to save waterlogged wooden objects is their proper conservation immediately after excavation from the wet environment. This involves the exchange of the water that fills the wood tissue for an appropriate chemical that will strengthen the wood structure and prevent its distortion, but unlike water, will not evaporate from the wood when exposed to air. Studies on conservation agents that meet such requirements have been conducted for years (Grattan 1982; Unger et al. 2001; Walsh et al. 2014; Imazu and Morgòs 1996; Christensen et al. 2012). Nevertheless, the most commonly used agent for the preservation of wet archaeological wood is still polyethylene glycol (PEG) (Jensen and Schnell 2004). However, the longstanding application of this conservation agent has shown that it has some serious drawbacks, which include leachability from wood under temperature and humidity changes; high hygroscopicity (especially low-molecular PEG); intense water absorption under relative humidity above $80 \%$; and vulnerability to oxidation reactions, for example, catalyzed by iron ions, which are often found in archaeological wood, leading to its depolymerization and formation of acids causing further chemical degradation of wood (Smith 2003; Olek et al. 2016; Bjordal 2012; Almkvist 2013; Almkvist and Persson 2007; Sandström et al. 2005). Therefore, there is still a need for further research on novel and effective agents for waterlogged archaeological wood conservation. One newly tested group of chemicals is organosilicon compounds, which include alkoxysilanes and methyltrimethoxysilane (MTMS) among others (De Vetter et al. 2009, 2010; Mai and Militz 2004; Andriulo et al. 2017). The results of previous research indicate that MTMS can effectively stabilize the dimensions of archaeological waterlogged wood differing in the degree of degradation (Broda and Mazela 2017; Broda et al. 2018).

In this work, wet archaeological elm (Ulmus spp.) wood was treated with a 50\% ethanol solution of MTMS. For comparison, waterlogged elm wood was also treated with $50 \%$ water solution of PEG 400 . Untreated wood fully saturated with water was used as a control. The main goal of the research was to investigate the drying dynamics of wet archeological elm wood treated with MTMS or PEG solutions using spectroscopy and gradient NMR methods. The distribution and the concentration of the two modifying agents were also studied along with their effect on the dimensional stability of waterlogged wood.

\section{Materials and methods}

\section{Wood samples}

Waterlogged archaeological elm was excavated from the Lednica Lake in the Wielkopolska Region (Broda and Mazela 2017). For MRI studies, $10 \times 10 \times 10 \mathrm{~mm}-$ sized cubic samples were cut from the elm log and their middle layers of a thickness of $1 \mathrm{~mm}$ were analyzed. For diffusion and SPI measurements, the elm wood samples were cut to fit the 5-mm NMR probe. The NMR signal in these experiments was collected from the whole sample. 


\section{Magnetic resonance imaging}

Magnetic resonance imaging (MRI) is a type of analysis that uses magnetic fields and radio waves to produce detailed images of the inside of a sample. Since the discovery of the method by Lauterbur and Mansfield (Lauterbur 1973; Mansfield and Grannell 1973), it has been successfully used in hospital diagnostics and basic research, including studies on wood (Gezici-Koç et al. 2017; Mikac et al. 2018; Kanazawa et al 2017; Žlahtič et al. 2017). Gezici-Koç et al. (2017) used MRI to study the state of water within a wood cell, and whether it is bound or free water, and used the data gained to determine the diffusion coefficient for several species of timber.

The method applies a time-dependent linear gradient field onto the static magnetic field to relate the magnetic field to the spatial position of the studied object. Because the nuclear magnetic resonance frequency, so-called Larmor frequency, is proportional to the magnetic field, there is a linear relationship between the resonant frequency and the spatial position. Tomographic images of the sample in 1D, 2D, or 3D display can be obtained with a spatial resolution of $\mu \mathrm{m}$. Depending on the chosen pulse sequence and parameters of the experiment, it is possible to measure the spin density $\rho(r)$, the spin-spin relaxation time $T_{2}$, the spin-lattice relaxation time $T_{1}$, or the diffusion $D$ weighted images. The tomographic image of the studied sample is obtained with a $\rho, T_{2}$, or $D$ contrast, respectively, because the intensity of every point of the image is proportional to one of the above parameters of the resonance nuclei (mainly protons) in this point. It is worth noting that the MRI is a noninvasive method, which allows studying the same sample as a function of time and thus eliminate the possible effect of the difference between samples on the result obtained. In the presented research, the multi-slice multi-echo (MSME) and single point imaging (SPI) MRI methods were used (Callaghan 1991; Kimmich 1997; Blümich 2000).

The pulse sequence in the MSME method generates a series of echoes, and the intensity of the image signal obtained is given by the following equation:

$$
S=\rho\left[1-\exp \left(-\frac{T_{R}}{T_{1}}\right)\right] \exp \left(-\frac{T_{E}}{T_{2}}\right),
$$

where $\rho$ is the spin density, $T_{2}$ the spin-spin relaxation time, $T_{1}$ the spin-lattice relaxation time, $T_{E}$ the echo time, and $T_{R}$ the repetition time. When $T_{R}$ is long enough $\left(\geq 5 T_{1}\right)$, the effect of this parameter on the image can be eliminated. This condition was fulfilled in the current experiments. Therefore, only $T_{2}$ and $\rho$ influenced the acquired proton images. The influences of $T_{2}$ and $\rho$ were separated and only the image with the $T_{2}$ and $\rho$ contrast was seen (Kimmich 1997; Blümich 2000). 2D images for the wood samples studied were collected and they provided a 2D spatial distribution of the spin-spin relaxation time and proton density of the treated elm samples. The 2D maps of $T_{2}$ and $\rho$ gave the corresponding 1D profile of the $T_{2}$ and $\rho$ of the studied conservation agent in any direction of the elm sample.

The MSME experiments were performed on a Bruker AVANCE $300 \mathrm{MHz}$ WB spectrometer equipped with imaging facilities. The static Bo field of 7.05 Tesla 
corresponds to the proton $\left({ }^{1} \mathrm{H}\right)$ Larmor frequency of $300.23 \mathrm{MHz}$. A Bruker imaging probehead Micro 2.5 was used with a $20-\mathrm{mm}$ birdcage coil, which allows the application of pulse gradients of up to $1 \mathrm{~T} \mathrm{~m}^{-1}$. The images were acquired with the repetition time $T_{R}$ of $4000 \mathrm{~ms}$, and the echo time $T_{E}$ was varied from 7 to $224 \mathrm{~ms}$. The acquisition parameters were a field-of-view (FOV) of $22 \times 22 \mathrm{~mm}$ digitized into $128 \times 128$ pixels with a slice thickness of $1 \mathrm{~mm}$ (i.e., each voxel equals 171 by 171 by $21 \times 10^{3} \mu \mathrm{m}$ ). The MRI measurements were taken at $23{ }^{\circ} \mathrm{C}$.

To illustrate the less mobile protons of the conservation agents used for the impregnation of the elm wood sample, the SPI method was applied (Gravina and Cory 1994). The SPI pulse sequence allows a single data point collection at a fixed encoding time, $t_{\mathrm{p}}$, after the radiofrequency pulse RF. The spatial dimension is phase encoded by cycling the magnetic field gradient amplitude along the $x, y$, or $z$-direction. The signal intensity $\mathrm{S}$ in the image is proportional to the local proton density $\rho$ of the sample studied:

$$
S=\rho \exp \left(-t_{p} / T_{2}\right)\left(\frac{1-\exp \left(T_{R} / T_{1}\right)}{1-\cos \theta \exp \left(-T_{R} / T_{1}\right)} \sin \theta\right)
$$

where $T_{R}$ is the repetition time, $\theta$ is the flip angle of RF pulse, and $T_{1}$ and $T_{2}$ are the spin-lattice and spin-spin relaxation times, respectively.

In the present work, the SPI method was used to obtain 1D images (or 1D profiles) of the proton density of the conservation agent filling archaeological elm wood. The profiles were acquired in the $z$-direction with $\mathrm{t}_{\mathrm{p}}=0.1 \mathrm{~ms}, F O V=15 \mathrm{~mm}$, and a resolution of $117 \mu \mathrm{m}$ at $23{ }^{\circ} \mathrm{C}$. The SPI method was implemented on a Bruker Avance III $\mathrm{HD}$ spectrometer operating at $500 \mathrm{MHz}$ of ${ }^{1} \mathrm{H}$ Larmor frequency and coupled to $11.4 \mathrm{~T}$

superconducting magnet. The spectrometer was equipped with a gradient unit allowing the application of a maximum gradient strength in the $z$-direction of $30 \mathrm{~T} \mathrm{~m}^{-1}$ and a diffusion probe with the coil of 5-mm diameter. The probe was used in the SPI method and in pulse-field gradient ${ }^{1} \mathrm{H}$ NMR diffusion experiments. Details of the MRI methods have been published elsewhere (Gravina and Cory 1994; Kimmich 1997; Blümich 2000); therefore, they are only discussed briefly here.

\section{Pulse gradient stimulated echo (PGSTE) NMR}

In the PGSTE, the attenuation of a measured spin-echo signal is due to molecular motions of the studied nuclei; in these experiments, the protons of the liquid are filling the cavities of elm wood. The motion takes place during the diffusion time $\Delta$ leading to phase-encoded echo signals. The attenuated signal is related to the experimental parameters by the following equation (Stejskal and Tanner 1965):

$$
\frac{S}{S_{o}}=\exp \left[-\gamma^{2} \delta^{2} g^{2} D\left(\nabla-\frac{\delta}{3}\right)\right],
$$

where $S$ and $S_{\text {o }}$ are echo signal intensities, with and without magnetic field gradient pulse applied, respectively, $\gamma$ is the gyromagnetic ratio, $\delta$ is the gradient pulse duration, and $D$ is the self-diffusion coefficient. 
The measurements were carried out as a function of the magnetic field gradient strength, $g$, that changed in 32 steps with a maximum gradient equal to 300,1500 , or $3000 \mathrm{G} / \mathrm{cm}$ depending on the experiment. The parameters $\delta$ and $\Delta$ were equal to $1 \mathrm{~ms}$ and $20 \mathrm{~ms}$, respectively, and remained unchanged during the measurements. The measurements were taken at $23{ }^{\circ} \mathrm{C}$.

For a homogeneous system, the echo signal decay is well described by Eq. (3). However, when diffusion takes place in an inhomogeneous system, as, for example, wood tissue with cavities and pores of various sizes, a distribution of the self-diffusion coefficient $D$ can occur and the observed echo decay is the sum of the function given by Eq. (3).

\section{Proton NMR spectroscopy}

${ }^{1} \mathrm{H}$ NMR spectra of the treated elm samples were conducted on a Bruker Avance III HD spectrometer. The experiments were performed at $23{ }^{\circ} \mathrm{C}$ applying simple $\pi / 2$ pulse to samples.

\section{Linear wood shrinkage}

The linear wood shrinkage, $\beta[\%]$, in tangential, radial, or longitudinal direction was calculated according to the following equation:

$$
\beta=\frac{l_{o}-l_{i}}{l_{o}} 100,
$$

where $l_{o}$ is the initial sample dimension (at the maximum moisture content) and $l_{i}$ is the dimension of the sample at a particular time of the drying procedure.

\section{Results and discussion}

\section{Drying process studied by MRI and NMR spectroscopy}

Figure 1 shows selected 2D MR images of $1 \mathrm{~mm}$-thick slice cut from the central part of a $10 \times 10 \times 10-\mathrm{mm}$ wooden block of archeological elm samples treated with $50 \%$ water solution of PEG 400 (b), 50\% ethanol solution of MTMS (c), and for comparison, also from an untreated sample fully saturated with water (a). Images were recorded during the drying process of wood until the content of the impregnating solutions or water became so low that it was no longer possible to record the NMR signal in the conditions of the MRI experiment. The images reflect the evaporation of the solvent applied (water or ethanol) from the whole cross section of the analyzed samples.

The signal intensity (the shade of gray) at every point of the images shown in Fig. 1 is proportional to the number of hydrogen nuclei (i.e., to the proton density) present in water or the conservation solution filling the archeological wood sample. However, the main chemical wood components (cellulose, hemicellulose, and 

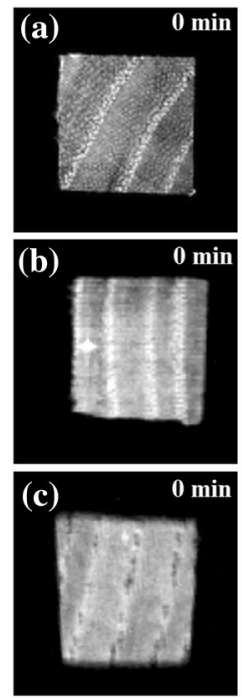
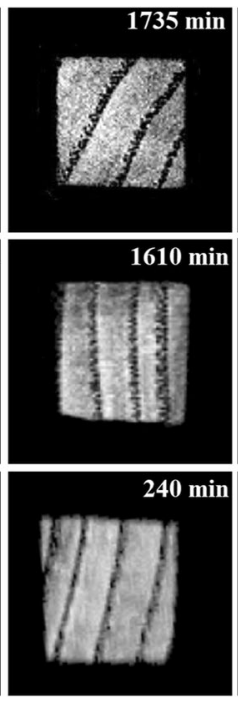

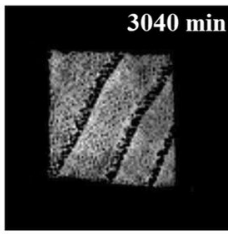

$3210 \mathrm{~min}$
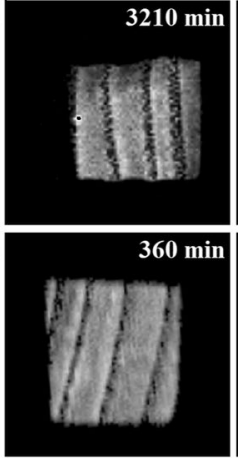
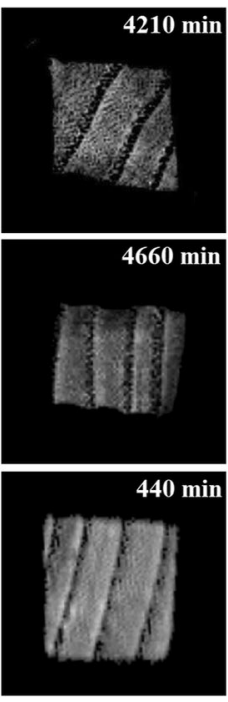
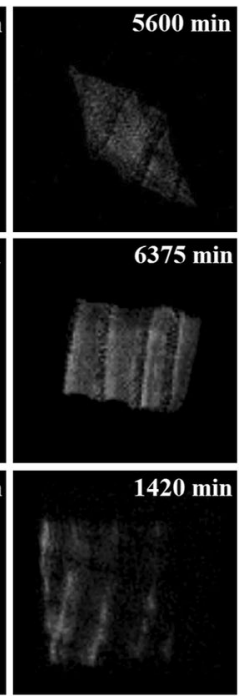

Fig. 1 2D tomographic images of archaeological elm samples recorded by the MSME method at different drying times: a untreated, b PEG-treated, and c MTMS-treated samples, respectively

lignin) also contain protons; the experimental setup in the conducted experiment did not allow us to detect their signal. SEM images of the examined archaeological elm wood (Broda and Mazela 2017) showed a heterogeneous wood microstructure: early wood and late wood areas, the inner cavities called the lumen cells, and the surrounding structural layer called the cell walls. The shape and size of the lumen cells are irregular and the thickness of the cell walls is different. Generally, the early wood of archeological elm is characterized by a less dense structure with large inhomogeneous lumens whereas the size of lumens in the late wood is much smaller, and thus, the structure is denser. The following interesting features can be observed from images seen in Fig. 1: clearly visible areas of early and late wood, changes in the sample dimensions during drying, and different duration of the drying process depending on the solvent applied. The signal intensity of water (Fig. 1a), PEG (Fig. 1b), and MTMS solution (Fig. 1c) in early wood areas of saturated samples is considerably higher compared to late wood. This is due to a different anatomical microstructure of late and early woods. Larger cavities of early wood contain more solvent in comparison with late wood, which results in a higher MRI signal. During the drying process, the solvents used evaporate faster from the larger cell lumina. Therefore, the early wood areas become darker in the first place because of the loss of protons from solvents and thus the loss of an MRI signal.

Visual inspection of the images clearly shows that untreated (saturated with $\mathrm{H}_{2} \mathrm{O}$ ) wood suffers the greatest deformation due to drying (Fig. 1a). On the other hand, MTMS-treated wood shows the highest dimensional stability compared to waterand even PEG-saturated samples. The shrinkage behavior of the tested samples measured in the radial and tangential directions is presented in Fig. 2. 
Generally, the contraction of the tested samples increased upon drying, but the size and rate of shrinkage depended on the conservation agent/solvent used. MTMStreated wood showed much higher stability against shrinkage compared with PEG. Shrinkage in both directions was comparable and was about $4 \%$, in contrast to the results observed for PEG-treated wood, where it was $35 \%$ and $8 \%$ in the tangential and radial directions, respectively. The shortest drying time was recorded for the MTMS-treated sample (about $1420 \mathrm{~min}$ ). A significantly longer time was necessary to dry PEG-treated and untreated samples (about 5600 and $6300 \mathrm{~min}$, respectively). After these times, no MR signal was visible under the experimental conditions applied.

To get more details on the drying process of archaeological wood treated with two different conservation agents, the 1D spin density profiles were determined from the images presented in Fig. 1. They are presented in Fig. 3 (left) along with the curves obtained on their basis showing the average change in the proton signal intensity during drying (right). The profiles were obtained along the horizontal line passing through the center of the corresponding tomographic images. The average signal intensity for a particular time of drying was calculated as shown in Fig. 3b, $\mathrm{d}, \mathrm{f}$. The distribution of water or conservation solutions is relatively uniform in late wood and uneven in early wood reflecting a more heterogeneous microstructure of this part of the sample. The main features of the sample drying process resulting from the data presented in Fig. 3 are as follows: the MRI signal intensity decreases with time as the sample dries and the signal decreases faster in early wood with larger cell lumina than in latewood with smaller cell lumina, regardless of the solvent applied. In the late wood, the amplitude decreases almost linearly as a function of the drying time in accordance with the loss of evaporable water or ethanol. In the early wood, the signal decay can be divided into two steps: the first one is characterized by the fast-initial decrease in the signal intensities and the second one, almost three times longer in the drying time scale, is described by a much smaller decay of the signal amplitude. The differences observed are due to the inhomogeneous microstructure of the early wood area in elm. The fast signal decay can be explained by the evaporation from the largest lumen and the pits connecting wood cells, and/or other

Fig. 2 Changes in wood shrinkage in the radial and tangential directions as a function of the time of drying depending on the treatment applied

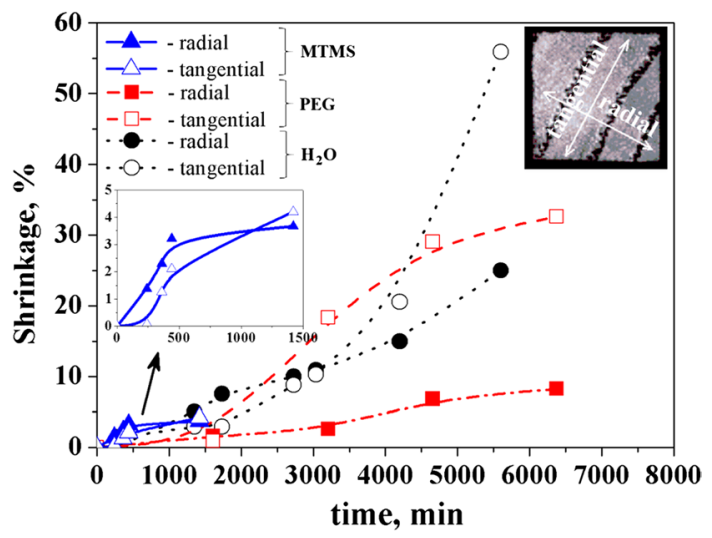



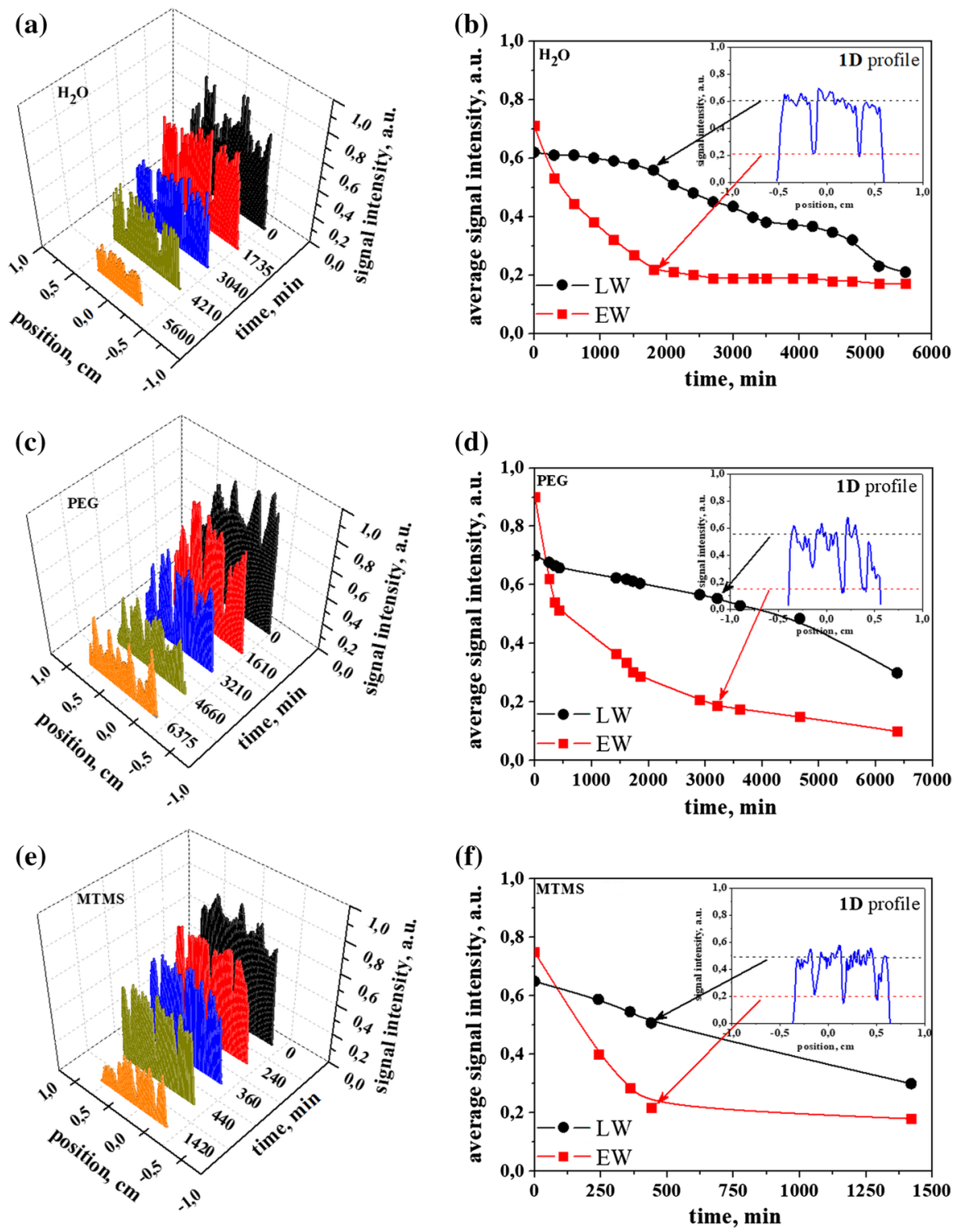

Fig. 3 1D proton intensity profiles (left column) along with the curves obtained on their basis showing the average change in the proton signal intensity during drying (right column). 1D profiles were obtained along the horizontal line passing through the center of the corresponding tomographic images shown in Fig. 1 for the archeological elm samples impregnated with a water, c PEG, and e MTMS solutions. The relationships between signal intensity and drying time (Fig. 2b, d, and f) are presented for early wood (EW) and late wood (LW) of treated elm wood

cavities found in early wood; the slow signal decay from the smaller lumen cells. The results presented above indicate that MRI is a very sensitive method, which enables to observe changes in the water/solvent content in wood. Therefore, it is also 
suitable for monitoring the drying process of archaeological wood conserved with different chemicals. However, the parameters used in the current MSME experiment allow monitoring only the solvents filling the cell lumina.

To study the impregnating solutions in the cell walls, the method of ${ }^{1} \mathrm{H}$ NMR high-resolution spectroscopy as well as SPI was applied. The dimension of the specimens used for these methods was limited by the size of the 5-mm RF coil of the NMR spectrometer and was much smaller compared to the samples used in the MSME experiment. The ${ }^{1} \mathrm{H}$ NMR signal in both experiments came from the protons of the solution of the whole sample tested. Figure 4 shows ${ }^{1} \mathrm{H}$ NMR spectra of PEG (left) and MTMS (right) in archaeological elm wood samples.

They were measured immediately after removal of the sample from the solution (before) and at a particular time of the drying process: after $24 \mathrm{~h}(1440 \mathrm{~min})$ in the case of PEG and after $1 \mathrm{~h}(60 \mathrm{~min})$ and $24 \mathrm{~h}$ (1440 min) for MTMS.

Peaks from water and PEG (Fig. 4 left) and ethanol and MTMS (Fig. 4 right) are visible in the spectra recorded for samples at the beginning of the drying process marked as "before". The intensity of the water peak in the spectrum of PEG (Fig. 4 left) significantly decreased after $24 \mathrm{~h}$ of drying indicating the evaporation of a lot of water. The water still remaining in the wood contributes to the signal that overlaps with the peak assigned to the PEG protons causing the asymmetry of this peak. The intensity of the ${ }^{1} \mathrm{H}$ NMR signal of PEG remains almost constant. In the ${ }^{1} \mathrm{H}$ NMR spectrum of the archeological wood treated with MTMS (Fig. 4, right) after $1 \mathrm{~h}$ of drying, the significant disappearance of the signal from ethanol can be seen as well as a significant decrease in the intensity of the signal assigned to MTMS protons and the change in this resonance peak positions upon drying. In addition, after $24 \mathrm{~h}$, a very significant broadening of this peak is observed, which makes the spectrum almost unmeasurable with the experimental parameters used. The broadening of the NMR line is usually caused by an increase in the proton-proton dipolar interaction, associated with the decrease in the mobility of molecules bearing interacting protons (Abragam 1996). The dynamics of the molecules studied may change due to the temperature change and/or the participation of molecules in different types of interaction, for example, in hydrogen bonding. Hydrogen bonding interaction is
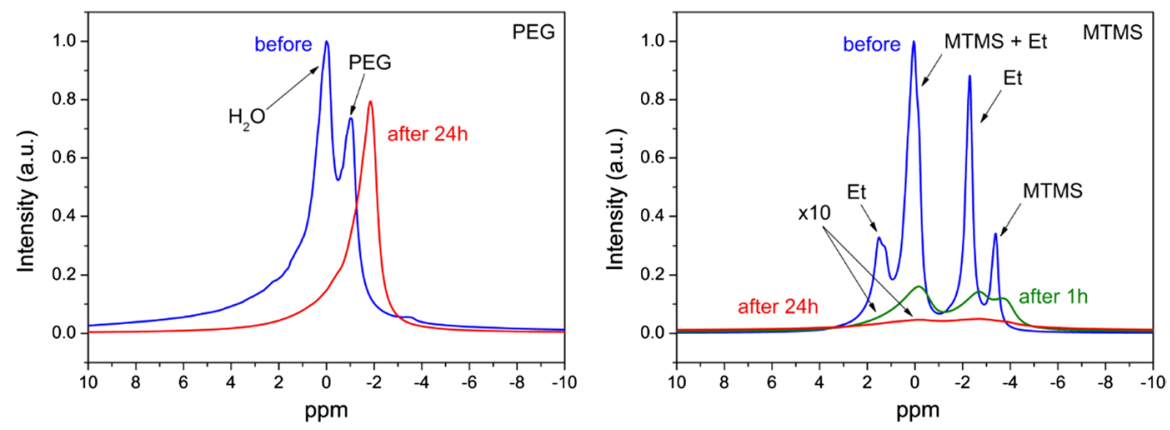

Fig. $4{ }^{1} \mathrm{H}$ NMR spectra of PEG (left) and MTMS (right) in the archaeological elm wood samples measured immediately after removal of the sample from the solution (before) and for a particular time of the drying process as shown in the figure 
one of the main factors that contribute to the chemical shift and cause the chemical shift of the proton signals in NMR spectra (Becker 1999). In this experiment, a constant temperature was maintained during the wood drying process. Therefore, the obtained spectra shown in Fig. 4 for wood treated with MTMS suggest that after evaporation of ethanol, the remaining MTMS molecules interact with the wood components. After $24 \mathrm{~h}$ of drying, most of the MTMS molecules are already involved in intermolecular interactions. This conclusion is supported by the SPI measurements presented in Fig. 5.

After $24 \mathrm{~h}$ of drying, a significant decrease in the intensity of the MTMS proton density profile is observed (Fig. 5 right). The observed signal probably comes from bound MTMS protons, but that can be measured in the conditions of the present experiment. The encoding time, $t_{\mathrm{p}}=0.1 \mathrm{~ms} \mu \mathrm{s}$ excludes from the current measurements of the very rigid MTMS molecules bound by hydrogen bonding with hydroxyl groups of hemicellulose, cellulose, and lignin-cellulose on the microfibrills surfaces. 1D SPI proton intensity profiles of PEG (Fig. 5 left) provide similar information to the spectra from Fig. 4. The drop in the signal intensities to about $40 \%$ of the initial value observed after $24 \mathrm{~h}$ of drying was caused by evaporation of a lot of water. It is worth noting that the 1D SPI proton density signals were collected from much smaller elm wood samples than in the MSME experiment. The magnetic gradient was applied in the longitudinal direction (parallel to the wood grain). The profile is the projection of the proton density from the entire sample to this axis. Therefore, contrary to the images obtained by MSME pulse sequence, SPI profiles do not distinguish between solvent signals from the early and late woods. They give the average signal from both areas of wood. The profiles shown in Fig. 5 indicate a homogeneous distribution of solvents in the microstructure of treated wood.

\section{Dynamics of conservation agents studied by relaxation and diffusion}

It is still a challenge to monitor the dynamics of impregnating solutions in the archeological wood during drying and to determine the parameters characterizing
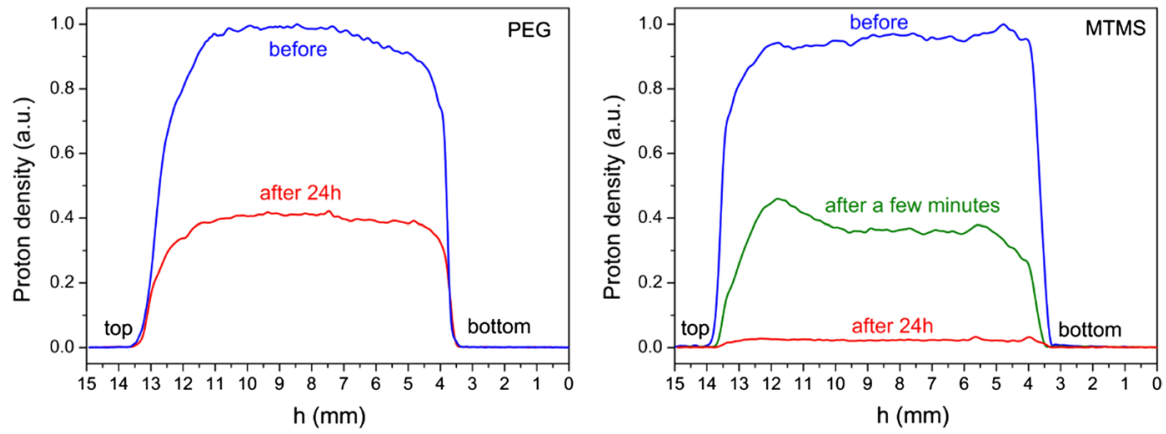

Fig. 5 1D SPI proton intensity profiles of PEG (left) and MTMS (right) filling the archeological elm wood samples measured immediately after removal of the sample from the solution (before) and for a particular time of the drying process as shown in the figure 
the dynamics by experimental methods. NMR methods were applied and these allowed the determination of the spin-spin relaxation time, $T_{2}$, and the self-diffusion coefficient, $D$, of conservation agent molecules (Stejskal and Tanner 1965; Kimmich 1997; Blümich 2000). Both parameters depend on the local proton environment of the molecule, in the present case preservative molecules, and reflect their mobility. Figure 6 shows 1D proton spin-spin relaxation time profiles (left) along with the curves obtained on their basis showing the average change in the proton $T_{2}$ values during drying (right). The profiles were obtained along the horizontal line passing through the center of the corresponding tomographic images shown in Fig. 1 for the archeological wet elm samples impregnated with PEG (Fig. 6a) and MTMS (Fig. 6c) solutions. The relationships between $T_{2}$ and drying time (Fig. 6b, d) are presented for early wood (EW) and late wood (LW).
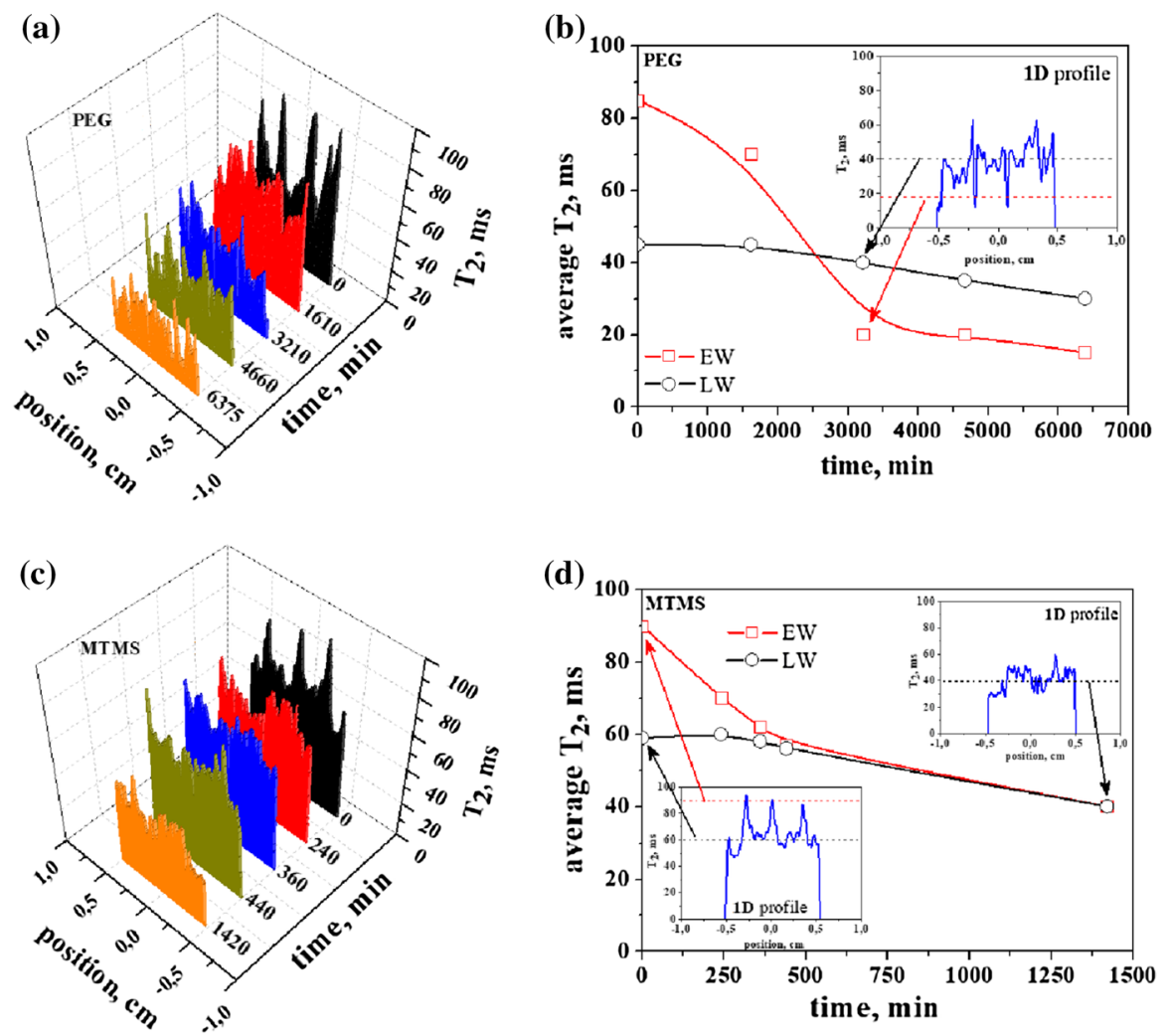

Fig. 6 1D proton spin-spin relaxation time profiles (left) along with the curves obtained on their basis showing the average change in the proton $T_{2}$ values during drying (right). The profiles were obtained along the horizontal line passing through the center of the corresponding tomographic images shown in Fig. 1 for the archeological elm samples impregnated with PEG and MTMS solutions. The relationships between $T_{2}$ and drying time (b, d) are presented for early wood (EW) and late wood (LW) of impregnated elm wood 
The hydrogen-containing molecules (i.e., the solution of PEG or MTMS) can randomly diffuse inside the cavities of the elm wood and collide with each other and with the cell walls. These interactions are the origin of $T_{2}$ relaxation. Generally, $T_{2}$ is longer for molecules diffusing freely (e.g., free solvent in large lumen cells) and shorter for molecules, whose mobility is restricted by small lumens or cavities, and very short for bound molecules. The same applies to the value of diffusion coefficients for solutions in wood. As seen in Fig. 6, the change in relaxation time resulting from drying the sample shows a similar character to that of the change in MRI signal intensity (Fig. 3, the right side); it decreases as a function of drying. Two relaxation times have also been distinguished and assigned to the solvent in the cell lumina of early and late woods. Cell lumina of early wood are larger and characterized by longer $T_{2}$ compared to late wood (Cox et al. 2010). However, this is only true for the specific drying time of the sample: about $3000 \mathrm{~min}$ in the case of PEG and about $500 \mathrm{~min}$ for MTMS. After these times, the $T_{2}$ of PEG and MTMS in the pores of early wood becomes less than or equal to the $T_{2}$ values in the pores of late wood. This finding, in the case of wood filled with PEG, can be explained as follows: after fast evaporation of PEG from the largest pores in early elm wood, some water molecules still remain in the smallest pores of early wood, which are much smaller than in late wood. Thus, the motion of water is more limited, which leads to a shorter $T_{2}$ compared to that characterizes the molecules in the pores of late wood. It cannot be ruled out, however, that after evaporation of free water, more mobile PEG molecules (for example, clusters with waters) contribute to the measured relaxation time. It should be mentioned that the relaxation time depicted in Fig. 6 is the average relaxation time. In the case of MTMS filling the elm wood sample, the $T_{2}$ relaxation time of the solvent in the lumina of early and late woods can be distinguished only up to about $400 \mathrm{~min}$, after that both times become equal. Taking into account the previously analyzed results obtained by the method of SPI and NMR spectroscopy, the relaxation results confirm that, after rapid evaporation of ethanol, the MTMS molecules remained in the cell lumina of the early and late woods. The diffusometry gives proof that some of them are bound (they can polymerize into longer chains or interact with wood polymers).

Figure 7 presents the decay of the echo signal intensities of PEG (left) and MTMS (right) filling the archeological elm wood measured during the drying process immediately after removal of the sample from the solution (before) and for a particular time of the drying process. The solid lines are the best fit for the modified Eq. (3) (with 2 or 3 components) to the experimental points. The diffusion measurements were taken on the small elm sample as in SPI, which fit the 5-mm NMR probe. The protons from a whole sample give the contribution to the echo decay amplitude measured. As a result, the average translational self-diffusion coefficients of protons coming from conservation agents present in elm wood were determined.

The diffusion of water in the lumen is much faster than the diffusion in the cell walls. The average translational self-diffusion coefficient, $D_{e v}$, of free water in the cell lumen is $\geq 10^{-9} \mathrm{~m}^{2} / \mathrm{s}$ depending on the size of the cells, whereas that of water in the cell wall is much longer. It was reported that water bound to cellulose fibers below fiber saturation point is characterized by $D_{e v} \geq 10^{-12} \mathrm{~m}^{2} / \mathrm{s}$ (Topgard and Soderman 2001). Therefore, one can assume that the self-diffusion coefficient for 

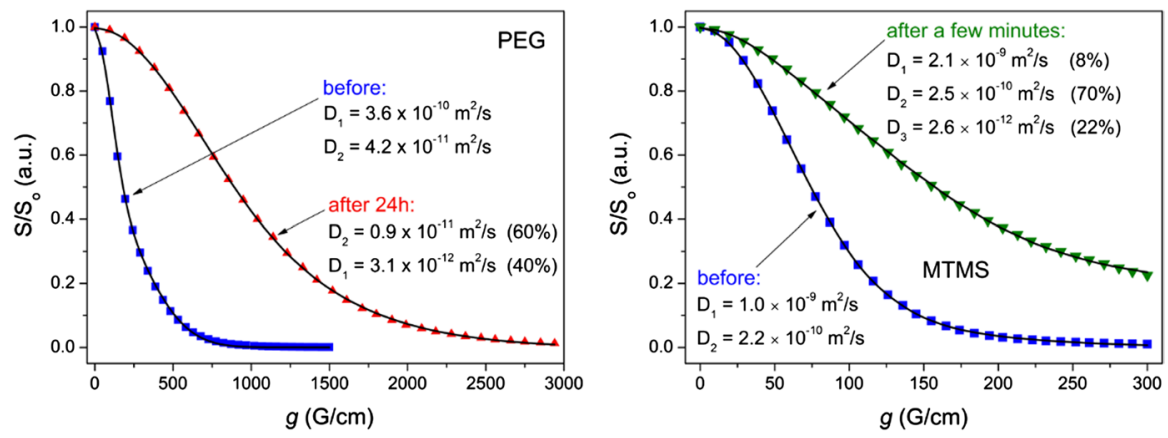

Fig. 7 Decay of the echo signal intensities of PEG (left) and MTMS (right) filling the wet elm wood measured during the drying process immediately after removal of the sample from the solution (before) and for a particular time of the drying process as shown in the figure. The solid lines are the best fit for the modified Eq. 3 to the experimental points. Diffusion coefficients obtained as a result of the fitting procedure are given in the figure

bound water in wood cell walls is of the same order of magnitude (Engelund et al. 2013; Terenzi et al. 2013). Similar values can be expected for other solvents.

The echo decays of PEG and MTMS shown in Fig. 7 at the starting point of drying, immediately after removal of the sample from the solution, are well fitted by two components yielding two $D_{e v}$ values denoted as $D_{1}$ and $D_{2}$. For elm wood treated with PEG, $D_{1}=3.6 \times 10^{-10} \mathrm{~m}^{2} / \mathrm{s}$ and $D_{2}=3.6 \times 10^{-11} \mathrm{~m}^{2} / \mathrm{s}$. For elm wood treated with MTMS, $D_{1}=3.6 \times 10^{-9} \mathrm{~m}^{2} / \mathrm{s}$ and $D_{2}=3.6 \times 10^{-10} \mathrm{~m}^{2} / \mathrm{s}$. The diffusion measurements were also taken for wood treated with PEG after $24 \mathrm{~h}$ of drying and for wood impregnated with MTMS, after a few minutes of drying. The results of the fitting procedure give two diffusion coefficients for PEG $\left(D_{1}=3.1 \times 10^{-12} \mathrm{~m}^{2} / \mathrm{s}\right.$ and $\left.D_{2}=0.9 \times 10^{-11} \mathrm{~m}^{2} / \mathrm{s}\right)$ and three diffusion coefficients for MTMS $\left(D_{1}=2.1 \times 10^{-9}\right.$ $\mathrm{m}^{2} / \mathrm{s}, D_{2}=2.5 \times 10^{-10} \mathrm{~m}^{2} / \mathrm{s}$, and $D_{3}=2.6 \times 10^{-12} \mathrm{~m}^{2} / \mathrm{s}$ ). In all cases, a single component does not fit the experimental data well.

According to the interpretation of the spin-spin relaxation time, two components of the self-diffusion coefficient obtained at the beginning of drying were also assigned to solvents in lumens of early wood (larger $D$ ) and late wood (smaller $D$ ). This interpretation is also valid for the results obtained at a later time of drying. The self-diffusion coefficient of PEG solvent in lumens of late wood $\left(D_{2}\right)$ does not change and is in the order of $10^{-11} \mathrm{~m}^{2} / \mathrm{s}$ (within $24 \mathrm{~h}$ of drying, water hardly evaporates from small lumens of elm late wood as shown in Fig. 3d). On the other hand, the average coefficient of solvent in lumens of early wood $\left(D_{1}\right)$ decreases during this time from $10^{-10}$ to $10^{-12} \mathrm{~m}^{2} / \mathrm{s}$. This is the result of the evaporation of water from larger cells, where there is not much left. The remaining water in the cells is water, mainly bound by hydrogen bonding with PEG and PEG alone, and this slows the dynamics of the solvent.

The self-diffusion coefficient of MTMS solvent in lumens of late wood $\left(D_{2}\right)$ also does not change in a few minutes after starting drying and is in the order of $10^{-10}$ $\mathrm{m}^{2} / \mathrm{s}$. However, in the case of MTMS in pores of early wood, two self-diffusion coefficients were distinguished: $D_{1}=2.1 \times 10^{-9} \mathrm{~m}^{2} / \mathrm{s}$ ( similar to that at the beginning of 
drying) and $D_{3}=2.6 \times 10^{-12} \mathrm{~m}^{2} / \mathrm{s}$. The $D_{1}$ coefficient is assigned to ethanol molecules rapidly evaporated from the large lumens of early wood. After a few minutes of drying, a small amount of ethanol still remains (its contribution to the echo decay is equal to $8 \%$ ). The $D_{3}$ coefficient is attributed to the MTMS bound to wood polymers. The contribution of such protons to the total echo decay signal is equal to $22 \%$.

\section{Conclusion}

The results presented in this paper clearly showed that MRI and NMR methods can be successfully used to observe the drying stage of a waterlogged archaeological wood conservation process with the use of PEG or MTMS. Due to the high sensitivity of the MRI method, it was possible to monitor the evaporation of particular solvents from the early and late wood areas of the elm wood during drying and also to demonstrate different dynamics of the applied conservation solutions inside the wood structure. The data obtained indicated a high probability of chemical modification of elm wood with silane, which would explain the observed high dimensional stability of wood treated with MTMS. However, the hypothesis of chemical binding of MTMS to wood polymers should be confirmed in further studies.

Acknowledgments This work was supported by the Polish Ministry of Science and Higher Education as a part of the "Cultural heritage research into innovative solutions and methods for historic wood conservation" project within the National Program for the Development of Humanities in 2016-2019 (Project No. 2 bH 15003783$)$.

\section{Compliance with ethical standards}

Conflict of interest On behalf of all authors, the corresponding author states that there is no conflict of interest.

Open Access This article is distributed under the terms of the Creative Commons Attribution 4.0 International License (http://creativecommons.org/licenses/by/4.0/), which permits unrestricted use, distribution, and reproduction in any medium, provided you give appropriate credit to the original author(s) and the source, provide a link to the Creative Commons license, and indicate if changes were made.

\section{References}

Abragam A (1996) The principles of nuclear magnetism. Oxford University Press, Oxford

Almkvist G (2013) Iron removal from waterlogged wood, Uppsala: Swedish University of Agricultural Sciences. SLU Repro, Uppsala

Almkvist G, Persson I (2007) Degradation of polyethylene glycol and hemicellulose in the Vasa. Holzforschung 62:64-70. https://doi.org/10.1515/HF.2008.009

Andriulo F, Giorgi F, Steindal CC, Kutzke H, Braovac S, Baglioni O (2017) Hybrid Nanocomposites made of diol-modified silanes and nanostructured calcium hydroxide. Applications to Alum-treated wood. Pure App Chem 89(1):29-39. https://doi.org/10.1515/pac-2016-1014

Becker ED (1999) High resolution NMR: theory and chemical applications. Academic Press, San Diego 
Bjordal CG (2012) Microbial degradation of waterlogged archeological wood. J Cult Herit 13(3):S118S122. https://doi.org/10.1016/j.culher.2012.02.003

Blümich B (2000) NMR imaging of materials. Oxford Science Publications, New York

Broda M, Mazela B (2017) Application of methyltrimethoxysilane to increase dimensional stability of waterlogged wood. J Cult Herit 25:149-156. https://doi.org/10.1016/j.culher.2017.01.007

Broda M, Majka J, Olek W, Mazela B (2018) Dimensional stability and hygroscopic properties of waterlogged archaeological wood treated with alkoxysilanes. Int Biodeter Biodegr 133:34-41. https://doi. org/10.1016/j.ibiod.2018.06.007

Bugani S, Modugno F, Lucejko JJ, Giachi G, Cagno S, Cloetens P, Janssens K, Morselli L (2009) Study on the impregnation of archaeological waterlogged wood with consolidation treatments using synchrotron radiation microtomography. Anal Bioanal Chem 395:1977-1985. https://doi.org/10.1007/ s00216-009-3101-5

Callaghan PT (1991) Principles of nuclear magnetic resonance microscopy. Oxford Science Publications, New York. https://doi.org/10.1002/ange.19931050256

Christensen M, Kutzke H, Hansen FK (2012) New materials used for the consolidation of archaeological wood-past attempts, present struggles, and future requirements. J Cult Herit 13(3):S183-S190. https ://doi.org/10.1016/j.culher.2012.02.013

Cox J, McDonald PJ, Gardiner BA (2010) A study of water exchange in wood by means of 2D NMR relaxation correlation and exchange. Holzforschung 64:259-266. https://doi.org/10.1515/ hf. 2010.036

De Vetter L, Stevens M, Van Acker J (2009) Fungal decay resistance and durability of organosilicontreated wood. Int Biodeter Biodegr 63(2):130-134

De Vetter L, Van den Bulcke J, Van Acker J (2010) Impact of organosilicon treatments on the wood-water relationship of solid wood. Holzforschung 64:463-468. https://doi.org/10.1515/hf.2010.069

Engelund ET, Thygesen LG, Svensson S, Hill CAS (2013) A critical discussion of the physics of woodwater interactions. Wood Sci Technol 47:141-161. https://doi.org/10.1007/s00226-012-0514-7

Gezici-Koç Ö, Erich SJF, Huinink HP, van der Ven LGJ, Adan OCG (2017) Bound and free water distribution in wood during water uptake and drying as measured by $1 \mathrm{D}$ magnetic resonance imaging. Cellulose 24(2):535-553. https://doi.org/10.1007/s10570-016-1173-x

Grattan DW (1982) A practical comparative study of several treatments for waterlogged wood. Stud Conserv 27:24-136. https://doi.org/10.2307/1506148

Gravina S, Cory DG (1994) Sensitivity and resolution of constant-time imaging. J Magn Reson B 104:53-61. https://doi.org/10.1006/jmrb.1994.1052

Imazu S, Morgòs A (1996) Conservation of waterlogged wood using sugar alcohol and comparison the effectiveness of lactitol, sucrose and PEG\# 4000 treatment. In: Proceedings of the 6th ICOM group on wet organic archaeological materials conference, pp 235-254

Jensen P, Schnell U (2004) The implications of using low molecular weight PEG for impregnation of waterlogged archaeological wood prior to freeze drying. In: Proceedings of the 9th ICOM group on wet organic archaeological materials conference, pp 279-308

Kanazawa Y, Yamada T, Kido A, Fujimoto K, Takakura K, Hayashi H, Fushimi Y, Kozawa S, Koizumi K, Okuni M, Ueda N, Togashi K (2017) Internal evaluation of impregnation treatment of waterlogged wood; relation between concentration of internal materials and relaxation time using magnetic resonance imaging. Magn Reson Imaging 38:196-201. https://doi.org/10.1016/j.mri.2017.01.010

Kimmich R (1997) NMR tomography, diffusometry, relaxometry. Springer, Heidelberg. https://doi. org/10.1007/978-3-642-60582-6

Lauterbur PC (1973) Image formation by induced local interaction: examples employing nuclear magnetic resonance (MRI). Nature 242:190-191. https://doi.org/10.1038/242190a0

Mai C, Militz H (2004) Modification of wood with silicon compounds. Treatment system based on organic silicon compounds—a review. Wood Sci Technol 37(6):453-461. https://doi.org/10.1007/ s00226-004-0225-9

Mansfield P, Grannell PK (1973) NMR diffraction in solids? J Phys C: Solid State Phys 6:L422. https:// doi.org/10.1088/0022-3719/6/22/007

Mikac U, Sersa I, Zupanc ZM, Humar M, Merela M, Oven P (2018) Application of MR microscopy for research in wood science. Micropor Mesopor Mat 269:51-55. https://doi.org/10.1016/j.micro meso.2017.03.025

Olek W, Majka J, Stempin A, Sikora M, Zborowska M (2016) Hygroscopic properties of PEG treated archaeological wood from the rampart of the 10th century stronghold as exposed in the 
Archaeological Reserve Genius loci in Poznań (Poland). J Cult Herit 18:299-305. https://doi. org/10.1016/j.culher.2015.08.002

Sandström M, Jalilehvand F, Damian E, Fors Y, Gelius U, Jones M, Salomé M (2005) Sulfur accumulation in the timbers of King Henry VIII's warship Mary Rose: a pathway in the sulfur cycle of conservation concern. Proc Natl Acad Sci USA 102(40):14165-14170. https://doi.org/10.1073/ pnas.0504490102

Siau JF (1984) Transport processes in wood. Springer Sciences \& Business Media, Berlin. https://doi. org/10.1007/978-3-642-69213-0

Smith CW (2003) Archaeological conservation using polymers: practical applications for organic artefact stabilization. A \& M University Press, College Station

Stejskal OE, Tanner JE (1965) Spin diffusion measurements: spin echoes in the presence of a timedependent field gradient. J Chem Phys 42:88-292. https://doi.org/10.1063/1.1695690

Terenzi C, Dvinskikh SV, Furo I (2013) Wood microstructure explored by anisotropic ${ }^{1} \mathrm{H}$ NMR line broadening: experiments and numerical simulations. J Chem Phys B 117:8620-8632. https://doi. org/10.1021/jp4043733

Topgard D, Soderman O (2001) Diffusion of water absorbed in cellulose fibbers studied by ${ }^{1} \mathrm{H}$ NMR. Langmuir 17:2694-2702. https://doi.org/10.1021/la0009821

Unger A, Schniewind A, Unger W (2001) Conservation of wood artifacts: a handbook. Springer, Berlin. https://doi.org/10.1007/978-3-662-06398-9

Walsh Z, Janeček ER, Hodgkinson JT, Sedlmair J, Koutsioubas A, Spring DR, Welch M, Hirschmugl KJ, Toprakcioglu C, Nitschke JR, Jones M, Scherman OA (2014) Multifunctional supramolecular polymer networks as next-generation consolidants for archaeological wood conservation. Proc Natl Acad Sci 111(50):17743-17748. https://doi.org/10.1073/pnas.1406037111

Žlahtič M, Mikac U, Serša I, Merela M, Humar M (2017) Distribution and penetration of tung oil in wood studied by magnetic resonance microscopy. Ind Crops Prod 96:149-157. https://doi.org/10.1016/j. indcrop.2016.11.049

Publisher's Note Springer Nature remains neutral with regard to jurisdictional claims in published maps and institutional affiliations. 